mostly in asides and footnotes. Those holding different views are accused of "dogmatic methods", "sweeping conclusions", "assertive bumptiousness", and other similar sins.

The Australian Acridoid fauna is still insufficiently known. Prior to the present work, 160 genera and 488 species have been described; in the three volumes now available 109 species are dealt with and forty-five of them are new. Judging from these figures, the total might reach some 800-900 species. The average number of pages per species is eight, due pertly to the verbosity of descriptions, but also to the method of quoting under each species every specimen studied, with its location; the vast majority of the specimens are in the collections of the Division of Entomology Museum, Commonwealth Scientific and Industrial Research Organization, Canberra, and this designation is repeated in full, for example, on pp. 169-74 of Vol. 3, in the case of one common species, no less than seventy-three times. It is not surprising that the first three volumes comprise 866 pages of text ; at this rate, the complete work should run to some 6,000 pages, or about twenty volumes. Although the price of a volume is reasonable, bearing in mind the excellent quality of the paper, careful printing and well-produced plates, both the size of the work and its total cost will scarcely make it suitable for the use of a practical entomologist even if he surmounts the difficulties inherent in the presentation of the material. Since the first three volumes have taken five years to publish, at least ten or fifteen more years would be required to complete the monograph, but when it is completed taxonomists will have cause to be grateful to the author for bringing together the available information on the Acridoid fauna of the Australian continent. Such shortcomings of the work as are mentioned above will matter less to specialists able to use it critically, than to economic entomologists. It is fortunate for the latter that some of the economically important genera of Australian Acrididae have in the meantime been revised (by Dr. K. H. L. Key) in a thoroughly critical and modern manner.

B. P. UVAROV

\section{THINKING AS A SKILL}

Thinking

An Experimental and Social Study. By Sir Frederic Bartlett. Pp. 203. (London: George Allen and Unwin, Ltd., 1958.) 18s. net.

" $\mathrm{NE}$ thing, at least, about thinking is absolutely certain. All the various ways in which it is practised by human beings have become possible only as a result of prolonged processes of biological development." It is not that many people now doubt the fact of mental evolution proclaimed in this first sentence of the book under notice; but some will be surprised by the experimental programme he deduces from it. It is argued that, in the study of thinking, we must make use of clues available from the study of simpler but related behaviour. Thinking may be treated as a complex and high-level kind of skill, that is, as a kind of superlative of the skills that have received so much attention lately in the laboratory.

Whatever the cogency of the inference, and there will, perhaps, be those who will deny that it is valid, this is an interesting and novel approach to the problem of thinking. Particularly in the hands of Sir Frederic Bartlett, who was for a long time director of the Applied Psychology Research Unit at Cambridge, and is now consultant thereto, it is a promising one, since we owe a large part of what is known about skills to the work done under his guidance at the Cambridge laboratory. A skilled action, says Prof. Bartlett, must show the proper 'timing'; in order to achieve this, the skilled man must, among other things, anticipate what is to come while reacting to what is already present. There is thus, in the total situation to which he reacts, a gap he must fill. Most skills involve a series of activities separated by intervening halts, discrete movements-'processes' as Aristotle might have called them had he known the word--with survey periods in between. The physiologist will think here of the complex skill of reading, the eye of a quick reader coming to rest three to five times over a line of newsprint, and most of the total reading-time being spent during these fixations. These general characteristics should be found in thinking, the most highly developed skill of all.

In accordance with this programme the filling of the anticipatory gap is demonstrated in the experimental studies of verbal and other interpolation and extrapolation, including the difficult case where the situation-items may be disguised in one way or another. The anagram of the crossword puzzle is given as an example. The idea of 'gap-completion' was exploited in a series of experiments by Selz, during 1913-26, and the programme puts it into a new context. The survey-period and what happens there is examined in an interesting experiment on the reading of maps, where "new decisions are called for at predetermined stages"; the process of making decisions has been investigated in many other contexts and Bartlett has thrown what may be called a biological light on its meaning. These experiments show, consistently with the results of other workers, habit or stereotype overcoming evidence which should cause one to break the habit. Interestingly, in these map experiments people seem to choose the course of action offering the greatest number of apparent possibilities. Can we see here the adventurous Cambridge man living dangerously ? The old problem of direction in thinking, worried at successively by Külpe, fifty years ago, and by the Gestalt psychologists, who indeed explained it by an extension of the gap principle, is given a new twist, perhaps as a sequel to the Cambridge elaboration of the airman's point of no return. Once activity, whether of movement or thinking, has reached a certain stage, the rest is predetermined, and there would seem to be little need of guidance towards the goal. The horse is, so to speak, on the home stretch. Something very like this was found in the experiments.

Perhaps the most exciting part of the book is contained in the last thirty-five pages, where are described certain experiments with a social theme. Situations involving social conflict were described, and subjects asked how these would eventuate. Would the merging religious factions stay united ?and so on. Here, too, the process of timing and the point of no return are shown to exist.

Both in the ingenious experiments and in the more theoretical discussions Bartlett does not claim quantitative results or any kind of finelity. As in his earlier book, "Remembering" (Cambridge, 1932), the experiments are simple, but the rewards great. The thought is powerful, but in parts not easy to follow. This is a notable book on a subject of great complexity ; it will be read for many years to come. 